\title{
Knowledge, Attitude and Practice of Primary Care Physicians in Dealing with Acute Stroke in Indonesia
}

\author{
Putu Jaya Kusuma', Lilik Djuari, M.D., Ph.D. ${ }^{2}$, Abdulloh Machin, M.D., Ph.D. ${ }^{3}$, \\ Asra Al Fauzi, M.D., Ph.D., FICS, FACS, IFAANS ${ }^{4}$
}

${ }^{1}$ Faculty of Medicine, Universitas Airlangga, Surabaya 60286, Indonesia.

${ }^{2}$ Department of Public Health and Preventive Medicine, Faculty of Medicine, Universitas Airlangga, Surabaya 60286, Indonesia. ${ }^{3}$ Department of Neurology, Faculty of Medicine, Universitas Airlangga, Surabaya 60286, Indonesia.

${ }^{4}$ Department of Neurosurgery, Faculty of Medicine, Universitas Airlangga/Dr. Soetomo General Academic Hospital, Surabaya Neuroscience Institute, Surabaya 60286, Indonesia.

Received 6 July 2020 • Revised 4 October 2020 • Accepted 20 October 2020 • Published online 8 April 2021

\begin{abstract}
:
Objective: There are still many things that interfere with the practice of effective acute stroke management, with one of them being the failure of health workers providing appropriate management. Hence, this study was conducted to evaluate the level of knowledge, attitude and practices of primary care physicians (PCPs) in acute stroke management in Indonesia.

Material and Methods: This cross-sectional face-to-face survey was conducted among all PCPs, from 63 primary health care centres; from October, 2019 to January, 2020 in Surabaya, Indonesia. A self-designed questionnaire, consisting of 25 questions, based on several guidelines, was used as the instrument of this survey.

Results: In total, 134 PCPs participated. The majority of their level of knowledge obtained was in the moderate category (51.5\%), while the majority of their attitude and practices towards stroke were in the good category $(67.9 \%$ and $75.2 \%)$. Nearly $75.0 \%$ of PCPs also knew about thrombolytic therapy, but only $<50.0 \%$ knew the 'golden period' of thrombolytic therapy. A significant correlation was found between PCPs knowledge-attitude ( $p$-value<0.001), knowledge-practices $(p$-value $=0.002)$ and attitude-practices ( $p$-value<0.001). There was also a significant difference in the level of stroke knowledge between PCPs, with different clinical practice experience ( $p$-value=0.015). Better stroke knowledge tended to be obtained by PCPs with younger clinical practice experience.
\end{abstract}

Contact: Asra Al Fauzi, M.D., Ph.D., FICS, FACS, IFAANS

Department of Neurosurgery, Faculty of Medicine, Universitas Airlangga/

Dr. Soetomo General Academic Hospital, Surabaya Neuroscience Institute,

Surabaya 60286, Indonesia.

E-mail: asra.al@fk.unair.ac.id

(c) 2021 JHSMR. Hosting by Prince of Songkla University. All rights reserved.

This is an open access article under the CC BY-NC-ND license

(http://www.jhsmr.org/index.php/jhsmr/about/editorialPolicies\#openAccessPolicy).
J Health Sci Med Res 2021;39(5):353-364 doi: 10.31584 /jhsmr.2021800 www.jhsmr.org 
Conclusion: The level of knowledge, attitude and practices of PCPs in acute stroke management in Indonesia is good, but should still be improved; especially knowledge about the use of thrombolytic therapy and its 'golden period.'

Keywords: acute, attitude, knowledge, practice, Primary Care Physicians, stroke

\section{Introduction}

Strokes are a major health problem, and the worldwide burden of stroke is increasing every year. Despite the rapid development of technology, strokes have remained as one of the leading causes of death, and the incidence of strokes has tended to increase in various countries over the past several decades. ${ }^{1-4}$ Globally, $70.0 \%$ of the total stroke incidence, and $87.0 \%$ of the total stroke-related deaths in the world are found in developing countries having low and medium income levels. ${ }^{5}$ In Indonesia alone, strokes are the highest cause of death in hospitals, with a mortality rate of $15.4 \%$, and the prevalence of strokes has increased from 7 cases per 1,000 per capita in 2013 , to 10.9 cases per 1,000 per capita in 2018. ${ }^{6,7}$

Even though an effective stroke therapy has been found, there are still many things that interfere with the practice of effective, acute stroke management ${ }^{8}$; especially in low-middle income countries. Four key barriers have been identified; including, barriers at the patients, health facilities, health professionals, and at the broader national health policy level. ${ }^{9}$ One of the things that can hamper an effective, acute stroke management is the failure of health workers in providing appropriate management in acute stroke settings ${ }^{10}$; including late identification of acute stroke symptoms and late, initial responses for acute stroke patients. Hence, this study was conducted to evaluate the level of knowledge, attitude and practices of primary care physicians (PCPs) in acute stroke management; especially in low-middle income countries, such as Indonesia.

\section{Material and Methods}

A cross-sectional face-to-face survey was conducted among all PCPs, from 63 primary health care centres from October, 2019 to January, 2020 in Surabaya, the second largest city in Indonesia; having a population of nearly 3 million people. Prior to the survey, all participants were informed as to the purpose of this study, and that it was voluntary to participate. Each participant, who agreed to participate, then signed an informed consent letter. The questionnaire was filled in by way of a closed-exam setting, and the whole process was supervised.

A self-design test questionnaire was developed in accordance with the Indonesian 2015 Clinical Practice Guidelines for Doctors in First Level Health Service Facilities $^{11}$ and the American Stroke Association (ASA) 2018 Guidelines for the Early Management of Patients with Acute Ischemic Stroke. ${ }^{12}$ The test questionnaire used included general information and characteristics of study participants (age, gender, job title, clinical experience time, clinical workplaces, recent stroke training attended in the last 12 months and number of acute stroke patients treated in the last 12 months), and 25 questions to assess participants knowledge, attitude and practice regarding acute strokes. To investigate the PCPs current knowledge regarding acute strokes, participants were asked to answer 10 multiple-choice questions, in regards to: stroke definition, classification, risk factors, initial symptoms, current management, prevention and rehabilitation, so as to assess the PCPs current attitudes regarding strokes, 10 general 
statements on a 5-item Likert scale were used. PCPs current practice of early management of suspected acute stroke patients were investigated, using 5 case scenarios in acute settings. For each scenario, the PCPs were asked to indicate their initial reaction in specific situations from predefined options. An initial face-to-face survey was conducted on 20 PCPs, who were randomly selected, and would not be involved in the data collection process. This initial survey was also carried out in a closed exam setting, with the whole process also being monitored in person. The results of this initial survey were used to estimate the response rate of the participants, and to test the questionnaires validity and reliability. Cronbach's Alpha and Pearson Product Moment test were then performed, using IBM Statistical Package for the Social Science for Windows (SPSS) Statistics 25 software, to assess the questionnaires validity and reliability before a final questionnaire was finally obtained.

PCPs characteristic, knowledge, attitude and practices were calculated using descriptive statistics. PCPs level of knowledge and practices towards stroke were measured by giving 10 points for correct answers and 0 points for incorrect answers. Thus, if all questions were answered correctly the total would be 150 points: 100 for PCPs level of knowledge, and 50 points for PCPs practices towards stroke. PCPs attitudes regarding strokes were measured by scoring each statement as 1-5 points, depending on the scale chosen. If the participants agreed with the statement, 5 points were given. On the other hand, if the participants disagreed with the statement, only 1 point was given. Thus, the PCPs attitude would receive a total score of 50 points; if they chose to agree with all of the statements given. Each of the PCPs scores on knowledge, attitude and practices was then divided into 3 categories: good, moderate, and lacking. The good category was obtained when the PCPs score was at least $80.0 \%$ of the total points available, while the moderate category was obtained when the PCPs score was a total of $50.0-80.0 \%$, and the lacking category was obtained when the PCPs final score was $<50.0 \%$ of the total score available. All available data was then tested using the non-parametric test method. Spearmann rank correlation analysis was used to calculate the correlation between PCPs knowledge-attitude, attitude-practices, and knowledge-practices regarding acute stroke. Mann Whitney $\mathrm{U}$ test and Kruskal Wallis $\mathrm{H}$ test were used to find differences in knowledge, attitude and practices; based on the PCPs characteristics. All tests were 2-tailed and statistical significance was set at a p-value $<0.050$. Statistical analyses were performed using IBM SPSS Statistics 25 software.

This study was approved by the ethics committees of the Faculty of Medicine, Universitas Airlangga (No.206/ EC/KEPK/FKUA/2019) and the Surabaya City Health Office.

\section{Results}

A total of 160 PCPs in Surabaya were successfully met face-to-face and given the questionnaires; however, only 134 PCPs gave their consent for this study (response rate $83.8 \%)$. Respondents consisted of: 111 (82.8\%) women and $23(17.2 \%)$ men, with an average age (S.D.) of 36.8 $( \pm 8.3)$ years. The age varied from a minimum of 26 years to a maximum of 61 years. Most PCPs had clinical practice experience $<10$ years, and $84.3 \%$ of PCPs had only 1 clinical practice location at the primary health care centre, while $14.7 \%$ of PCPs had 2 clinical practice locations. The majority of PCPs had treated 1-5 cases of acute stroke $(63.4 \%)$, and had attended at least one stroke training $(53.7 \%)$ in the last 12 months. Further characteristics are shown in Table 1.

Based on the results of this study, it was found that the level of stroke knowledge of PCPs has an average score of 72.31 ( \pm 15.36$)$, with $51.5 \%$ of PCPs being in the moderate category. In addition, $43.3 \%$ of PCPs were in the good category, with $5.2 \%$ having lacking stroke knowledge. Around half of the PCPs knew the stroke definition and criteria well. Ninety percent of the PCPs also answered 
the questions regarding stroke classifications, risk factors and initial symptoms correctly. Around $62.0 \%$ of the PCPs correctly answered the question about stroke prevention, and $50.0 \%$ knew the recommended rehabilitation for stroke patients. Nearly $75.0 \%$ of PCPs also knew about the thrombolytic therapy used for acute stroke management, but only $<50.0 \%$ knew the 'golden period' of thrombolytic therapy. Table 2 shows the different levels of knowledge, based on the characteristics of the PCPs. There was a significant difference between the level of stroke knowledge of the PCPs, with different clinical practice experiences ( $p$-value=0.015). Better knowledge tended to be obtained by PCPs with clinical practice experience of 0-10 years, compared to $10-20$ or $>20$ years. There were no significant differences between the level of knowledge of the PCPs in concerns to: different genders, clinical practice location, stroke training attendance and number of acute stroke patients treated in the last 12 months ( $p$-value>0.050).
Table 1 Primary care physicians characteristics $(n=134)$

\begin{tabular}{lll}
\hline Variable & Number & $(\%)$ \\
\hline Age (years) & & \\
$26-35$ & 70 & $(52.2)$ \\
$36-45$ & 43 & $(32.1)$ \\
$>45$ & 21 & $(15.7)$ \\
Gender & & \\
$\quad$ Female & 111 & $(82.8)$ \\
$\quad$ Male & 23 & $(17.2)$ \\
Clinical practice experience (years) & & \\
$\quad 0-10$ & 74 & $(55.2)$ \\
$11-20$ & 43 & $(32.1)$ \\
$>20$ & 18 & $(12.7)$ \\
Clinical practice location & & \\
$\quad$ Only one & 21 & $(15.7)$ \\
$\quad$ More than one & 113 & $(84.3)$ \\
Number of acute stroke patients treated in & & \\
the last 12 months & & \\
$\quad 0$ & 39 & $(29.1)$ \\
1-5 & 85 & $(63.4)$ \\
$>5$ & 10 & $(7.5)$ \\
Having attended at least one stroke training & & \\
in the last 12 months & & \\
Yes & 72 & $(53.7)$ \\
No & 62 & $(46.3)$ \\
\hline
\end{tabular}

Table 2 Different levels of knowledge based on the primary care physicians characteristics $(n=134)$

\begin{tabular}{|c|c|c|c|c|}
\hline \multirow{3}{*}{ Variable } & \multicolumn{3}{|c|}{ Knowledge } & \multirow{3}{*}{$p$-value } \\
\hline & & & Lacking & \\
\hline & Number (\%) & Number (\%) & Number (\%) & \\
\hline Gender & & & & 0.828 \\
\hline Female & $47(42.3)$ & $60(54.1)$ & $4(3.6)$ & \\
\hline Male & $11(47.8)$ & $9(39.1)$ & $3(13.0)$ & \\
\hline Clinical practice experience (years) & & & & $0.015^{\star}$ \\
\hline $0-10$ & $42(56.8)$ & $29(39.2)$ & $3(4.1)$ & \\
\hline $11-20$ & $11(256)$ & $30(69.8)$ & $2(4.7)$ & \\
\hline$>20$ & $5(29.4)$ & $10(58.8)$ & $2(11.8)$ & \\
\hline Clinical practice location & & & & 0.130 \\
\hline Only one & $8(38.1)$ & $11(52.4)$ & $2(9.5)$ & \\
\hline More than one & $50(44.2)$ & $58(51.3)$ & $5(4.4)$ & \\
\hline Number of acute stroke patients treated in the last 12 months & & & & 0.332 \\
\hline 0 & $15(38.5)$ & $19(48.7)$ & $5(12.8)$ & \\
\hline $1-5$ & $40(47.1)$ & $43(50.6)$ & $2(2.4)$ & \\
\hline$>5$ & $3(30.0)$ & $7(70.0)$ & $0(0.0)$ & \\
\hline Having attended at least one stroke training in the last 12 months & & & & 0.226 \\
\hline Yes & $34(47.2)$ & $36(50.0)$ & $2(2.8)$ & \\
\hline No & $24(38.7)$ & $33(53.2)$ & $5(8.1)$ & \\
\hline
\end{tabular}

*Variable statistically significant ( $p$-value<0.050) 
This study found that the PCPs attitude toward stroke had an average score of 83.31 , and that the majority of PCPs $(67.9 \%)$ have a good attitude towards stroke. In addition, $29.9 \%$ PCPs were in the moderate category and $2.2 \%$ had lacking stroke attitude. PCPs view and attitudes towards stroke are presented in Table 3. There were no significant differences between PCPs attitudes towards stroke regarding; different genders, clinical practice experience, clinical practice location, stroke training attendance and number of acute stroke patients treated in the last 12 months ( $p$-value>0.050). In this study a positive and significant correlation of knowledge-attitude of PCPs was found ( $p$-value<0.001).

The PCPs current practices towards stroke have an average score of 81.49 , and majority of PCPs $(75.2 \%)$ have a good practice towards stroke. In addition, 17.2\% PCPs are in the moderate category and $7.5 \%$ have lacking stroke practice. Eighty percent of PCPs have been able to give correct, initial management to suspected stroke patients with decreased consciousness, by stabilizing the cardiopulmonary system first. More than $80.0 \%$ of PCPs have been able to provide good, initial management for stroke suspected patients with hyperglycaemia and hypoglycaemia, but only $60.0 \%$ have been able to provide good, initial management for stroke patients with hypertension; who will be given thrombolytic therapy. There are no significant differences between PCPs current practices towards stroke with different genders, clinical practice experience, clinical practice location, stroke training attendance and number of acute stroke patients treated in the last 12 months ( $p$-value>0.050). In this study a positive and significant correlation of knowledge-practice and attitude-practice of PCPs was found ( $p$-value $=0.002$ and $p$-value $<0.001$, respectively).

Table 3 Primary care physicians view and attitude toward stroke $(n=134)$

\begin{tabular}{|c|c|c|c|c|}
\hline Attitude & $\begin{array}{l}\text { Rather disagree } \\
\text { Number }(\%)\end{array}$ & $\begin{array}{l}\text { Neutral } \\
\text { Number (\%) }\end{array}$ & $\begin{array}{l}\text { Rather agree } \\
\text { Number }(\%)\end{array}$ & $\begin{array}{l}\text { Agree } \\
\text { Number (\%) }\end{array}$ \\
\hline Stroke is one of the leading causes of death in the world & $13(9.7)$ & $11(8.2)$ & $86(64.2)$ & $24(17.9)$ \\
\hline All types of strokes are a medical emergency & $5(3.7)$ & $4(3.0)$ & $71(53.0)$ & $54(40.3)$ \\
\hline Stroke patients should be given treatment as soon as possible & $0(0.0)$ & $1(0.7)$ & $66(49.3)$ & $67(50.0)$ \\
\hline $\begin{array}{l}\text { Speed in providing initial treatment greatly affects the prognosis of } \\
\text { stroke patients }\end{array}$ & $0(0.0)$ & $16(11.9)$ & $47(35.1)$ & $71(53.0)$ \\
\hline $\begin{array}{l}\text { The increased prevalence and mortality of strokes need to be } \\
\text { taken seriously }\end{array}$ & $0(0.0)$ & $3(2.2)$ & $83(61.9)$ & $48(35.8)$ \\
\hline Stroke can cause disability for a lifetime & $7(5.2)$ & $3(2.2)$ & $68(50.7)$ & $56(41.8)$ \\
\hline Stroke can be cured & $3(2.2)$ & $9(6.7)$ & $96(71.6)$ & $26(19.4)$ \\
\hline Stroke can be prevented & $2(1.5)$ & $1(0.7)$ & $72(53.7)$ & $59(44.0)$ \\
\hline $\begin{array}{l}\text { All stroke suspected patients should be immediately taken to the } \\
\text { nearest hospital }\end{array}$ & $4(3.0)$ & $2(1.5)$ & $72(53.7)$ & $56(41.8)$ \\
\hline $\begin{array}{l}\text { Initial management of a stroke patients must be carried out by } \\
\text { PCPs }\end{array}$ & $1(0.7)$ & $0(0.0)$ & $82(61.2)$ & $51(38.1)$ \\
\hline
\end{tabular}

The "disagree" column is not shown because none were filled $\mathrm{PCPs}=$ primary care physicians 


\section{Discussion}

In an acute stroke setting, early stroke managements are required as soon as possible to achieve a better stroke outcome. Identification of stroke symptoms can be very challenging in the acute settings, because stroke symptoms can vary depending on the cause of the stroke, the location of the stroke as well as other disorders that accompany strokes. ${ }^{13}$ Hence, an effective interaction and collaboration between all components involved in initial stroke response is needed, including identification of symptoms, transportation and pre-hospital management of strokes. ${ }^{8}$ All components involved in initial stroke response must be well-prepared in order to achieve such things.

This cross-sectional study presents primary data on knowledge, attitude and practices of PCPs in acute stroke management; especially in low-middle income countries, such as Indonesia. In this study, it was found that the average level of knowledge of PCPs regarding acute stroke was in the moderate category, while the attitude and practices of PCPs towards stroke were in the good category. This study revealed that there was a slight gap between the PCPs level of knowledge and PCPs attitude and practices towards stroke. This small gap is probably due to the PCP's lack of knowledge regarding thrombolytic therapy; especially its 'golden period.' This could be due to, thrombolytic therapy being considered as a relatively new, emerging therapy in Indonesia, which is not largely available to all health facilities. In addition, the lack of PCPs knowledge about the 'golden period' of thrombolytic therapy can also be caused by the fact that the current use of thrombolytic therapy in Indonesia is not part of the PCPs competency.

In this study, almost $90.0 \%$ of the PCPs know about the classification, risk factors and early symptoms of a stroke well. This finding is consistent with previous studies, which stated that: the knowledge about stroke risk factors among health workers and in the general population were considered good, with hypertension being the most often recognized risk factor of stroke; both by health workers and the general population. ${ }^{14-17}$ PCPs' knowledge of early stroke symptoms in this study is slightly better than the previous study, which stated that: at least $25.0 \%$ of health workers failed to recognize the initial symptoms of stroke. ${ }^{18}$ Previous studies also found that one-sided body weakness is the initial symptom of stroke, which is most commonly recognized by the general population as well as the stroke patients themselves..$^{10,14,17,19,20}$ A good level of knowledge about risk factors and early symptoms of stroke are certainly very important for PCPs in promoting stroke prevention and recognition in the community. Especially, considering that the PCPs are the most reliable source of information for the general population and the patients themselves. ${ }^{16,17,20}$

More than half of the PCPs know the recommended prevention and rehabilitation for stroke patients. Stroke prevention can be divided into primary and secondary prevention. Primary prevention aims to reduce the development of stroke risk factors, while secondary prevention focuses more on the treatment of emerging stroke risk factors. Rehabilitation in stroke patients should aim to optimize the recovery of physical, neurological, and psychological functions of stroke patients. Patient education regarding stroke symptoms, risk factors, prevention, initial responses and rehabilitation are also needed to reduce the risk of recurrent strokes. ${ }^{8}$ Nearly $75.0 \%$ of PCPs also know about thrombolytic therapy. used for acute stroke management; however, only $<50.0 \%$ knew the "golden period' of thrombolytic therapy. These results are slightly better than previous studies, which found that only $31.0 \%$ of the general population and $49.0 \%$ of health workers knew about thrombolytic therapy for acute stroke treatment, with only $47.9 \%$ of health workers knowing about the "golden period' of thrombolytic therapy. ${ }^{10,20}$

Regarding the PCPs attitudes and practices towards stroke, our findings were encouraging with the majority of 
PCPs having a positive attitude towards effective stroke management. The majority of PCPs also managed to answer 4 out of 5 questions in concerns to the current, initial management and pre-hospital stroke practices. Most of the PCPs have been able to provide good, initial management for stroke suspected patients with decreased consciousness, hypoglycaemia, hyperglycaemia and even hypertension. There were more than $90.0 \%$ of PCPs who agreed that all types of strokes should be considered as a medical emergency, and that stroke suspected patients should be taken to the nearest hospital to get treated as soon as possible, because the speed and accuracy in the initial management of stroke suspected patients could determine the success rate of stroke therapy. This finding is consistent with a previous study, which found that the majority of PCPs agreed that acute strokes and TIAs are medical emergencies and immediate treatments are needed as soon as possible. ${ }^{21}$ One thing to remember is that effective stroke managements are not the only factors that determines the outcome of stroke patients.

There is a significant difference between the level of stroke knowledge of PCPs with different clinical practice experiences, with better stroke knowledge tending to be obtained by PCPs with clinical practice experience of $0-10$ years, compared to $10-20$ or $>20$ years. Similar difference was not found in the PCPs attitude and current practices towards stroke. Previous studies found that there were no significant differences between the knowledge, attitude and practices of health workers with different levels of clinical practice experience..$^{15,18,19}$ In this study, higher stroke knowledge tends to be obtained by PCPs with younger clinical practice experience; especially knowledge about thrombolytic therapy and the 'golden period' of thrombolytic therapy. This could be due to thrombolytic therapy being one of the relatively new, emerging therapies, which is not largely available to all health facilities in Indonesia. So PCPs with older clinical practice experience might not be accustomed to the use of thrombolytic therapy. It seems that there is still a need to conduct knowledge and training updates related to acute stroke management, through symposiums or workshops for PCPs and other medical personnel regularly. There were no significant differences between the level of stroke knowledge, attitude, and current practices of PCPs in concerns to: different genders, clinical practice location, stroke training attendance and number of acute stroke patients treated, this was also found in previous studies. ${ }^{15,18,19,22}$

This study has several limitations. First, the PCPs involved in this study are only from primary health care centres in Surabaya; therefore, these findings may not be generalizable to the entire country. Further research is needed to confirm our findings. Second, the knowledge, attitude and practices of PCPs in this study are selfreported, and it may not determine actual PCPs practice in acute stroke settings. Nevertheless, this face-to-face survey had a response rate of $83.8 \%$, and provides a fair opportunity for all PCPs to assess their knowledge, attitude and practices in acute strokes; additionally, the whole process was supervised.

\section{Conclusion}

From this study it can be concluded that the level of knowledge, attitude and practices of PCPs in acute stroke management in Indonesia are reasonably good, but should still be improved; especially, knowledge about the use of thrombolytic therapy and the 'golden period' of thrombolytic therapy in acute stroke management. Regular training related to acute stroke management, through symposiums or workshops for PCPs and other medical personnel as well as a campaign to increase stroke awareness in the general population of Indonesia are required. Further research, on a larger scale is needed to confirm the findings of this study. 


\section{Conflict of interest}

The authors confirm that there are no known conflicts of interest associated with this study, and there was no significant financial support for this work that could have influenced its outcome.

\section{References}

1. Pandian JD, Jaison A, Deepak SS, Kalra G, Shamsher S, Lincoln DJ, et al. Public awareness of warning symptoms, risk factors, and treatment of stroke in Northwest India. Stroke 2005;36: 644-8.

2. Pontes-Neto OM, Silva GS, Feitosa MR, de Figueiredo NL, Fiorot JA, Rocha TN, et al. Stroke awareness in Brazil. Stroke 2008;39:292-6.

3. Thrift AG, Thayabaranathan T, Howard G, Howard VJ, Rothwell PM, Feigin VL, et al. Global stroke statistics. Int J Stroke 2016;12: 13-32.

4. Venketasubramanian N, Yoon BW, Pandian JD, Navarro JC. Stroke epidemiology in South, East, and South-East Asia: a review. J Stroke 2018;20:142

5. Johnson W, Onuma O, Owolabi M, Sachdev S. Stroke: a global response is needed. Bulletin of the World Health Organization 2016;94:634-634A.

6. Ministry of Health, Indonesia. Basic Health Reseaech (Riskesdas) in Indonesia 2018. Jakarta: Ministry of Health, Indonesia; 2018.

7. Ministry of Health, Indonesia. Basic Health Reseaech (Riskesdas) in Indonesia 2007. Jakarta: Ministry of Health, Indonesia; 2007.

8. Schwamm LH, Pancioli A, Acker JE, Goldstein LB, Zorowitz RD, Shephard TJ, et al. Recommendations for the establishment of stroke systems of care. Stroke 2005;36:690-703.

9. Baatiema L, de-Graft Aikins A, Sav A, Mnatzaganian G, Chan $\mathrm{CKY}$, Somerset $\mathrm{S}$. Barriers to evidence-based acute stroke care in Ghana: a qualitative study on the perspectives of stroke care professionals. BMJ Open 2017;7:e015385.

10. Mellon L, Hasan H, Lee S, Williams D, Hickey A. Knowledge of thrombolytic therapy amongst hospital staff. Stroke 2015; 46:3551-3.

11. Ministry of Health, Indonesia. Indonesian clinical practice guidelines for doctors in the first level health service facilities 2015. Jakarta: Ministry of Health, Indonesia; 2015.
12. Powers WJ, Rabinstein AA, Ackerson T, Adeoye OM, Bambakidis NC, Becker K, et al. 2018 guidelines for the early management of patients with acute ischemic stroke: a guideline for healthcare professionals from the American Heart Association/ American Stroke Association. Stroke 2018;49:e46-99.

13. Bustamante A, López-Cancio E, Pich S, Penalba A, Giralt D, García-Berrocoso T, et al. Blood biomarkers for the early diagnosis of stroke. Stroke 2017;48:2419-25.

14. Akinyemi RO, Ogah OS, Ogundipe RF, Oyesola OA, Oyadoke AA, Ogunlana MO, et al. Knowledge and perception of stroke amongst hospital workers in an African community. Eur $\mathrm{J}$ Neurol 2009;16:998-1003.

15. Madae'en SS, Bulatova NR, Al-Qhewii TA, Sakran LH, El-Zayyat $\mathrm{HH}$, Kamar MKA, et al. Stroke awareness in the general population: a study from Jordan. Trop J Pharm Res 2013;12: 1071-6.

16. Müller-Nordhorn J, Nolte $\mathrm{CH}$, Rossnagel $\mathrm{K}$, Jungehülsing GJ, Reich A, Roll S, et al. Knowledge about risk factors for stroke. Stroke 2006;37:946-50.

17. Saengsuwan J, Suangpho P, Tiamkao S. Knowledge of stroke risk factors and warning signs in patients with recurrent stroke or recurrent transient ischaemic attack in Thailand. Neurol Res Int 2017. doi: 10.1155/2017/8215726.

18. Yang J, Zhang J, Ou S, Wang N, Wang J. Knowledge of Community general practitioners and nurses on pre-hospital Stroke Prevention and Treatment in Chongqing, China. PLoS One 2015;10. doi: 10.1371/journal.pone.0138476.

19. Adelman EE, Meurer WJ, Nance DK, Kocan MJ, Maddox KE, Morgenstern LB, et al. Stroke awareness among inpatient nursing staff at an academic medical center. Stroke 2014;45: 271-3.

20. Kim YS, Park SS, Bae HJ, Heo JH, Kwon SU, Lee BC, et al. Public awareness of stroke in Korea. Stroke 2012;43:1146-9.

21. Roebers S, Wagner M, Ritter MA, Dornbach F, Wahle K, Heuschmann PU. Attitude and current practice of primary care Physicians in Acute Stroke Management. Stroke 2007; 38:1298-303.

22. Adusumilli D, Syed S. Community stroke awareness: knowledge, attitude, and health-seeking behavior of adults in an urban slum of Hyderabad, India. Int J Med Sci Public Health 2018;7: 848-53. 


\section{Supplementary}

Questionnaire of knowledge, attitude, and practice of primary care physicians in acute stroke management in Indonesia

\section{General information}

Age:

Sex:

Job title:

Clinical workplaces:

Clinical experience time:

Recent stroke training attended in the last 12 months:

Number of acute stroke patients treated in the last 12 months:

\section{Knowledge}

Please choose an answer that you think is the most correct and most suitable for you according to your current situation.

1. Which of the following is not considered as the WHO criteria in defining stroke?
a. Impaired brain function
b. Lasts for 24 hours
c. Caused by a neurovascular disorders
d. Causes severe headaches

2. The following are some of the types of stroke, except:
a. Subarachnoid hemorrhage
b. Intracerebral hemorrhage
c. Embolic stroke
d. Idiopathic stroke

3. Which of the following risk factors is less likely to be found in stroke cases?
a. Hypertension
b. Dyslipidemia
c. Atrial Fibrillation
d. HIV

4. Which of the following is less likely to be considered as the cause of stroke?
a. Cerebral aneurysm rupture
b. Intracranial arteries Atherosclerosis
c. Meningoencephalitis
d. Brain Arteriovenous malformations rupture 
5. Which of the following early stroke symptoms is not included in the FAST term?
a. Facial asymmetry
b. Headache
c. Sudden weakness of the arm
d. Speech disorders

6. Which of the following is not considered as one of the primary prevention efforts in stroke?
a. Reducing fat consumption
b. Quit smoking
c. Regular exercise
d. Early hypertension management

7. The following are some of the efforts that PCP can do in rehabilitating stroke patients, except:
a. Asking the patient to exercise regularly
b. Providing a post-stroke education
c. Handling psychological problems that may arise in stroke patients
d. Prescribing thrombolytic therapy for 1 year

8. Which of the following is still considered to be the most effective therapy in acute stroke management?
a. Thrombolytics
b. Anticoagulants
c. Antiplatelets
d. Statins

9. Which of the following is the golden period limit in the administration of thrombolytic therapy in stroke patients?
a. 6 hours from onset
b. 5.5 hours from onset
C. 5 hours from onset
d. 4.5 hours from onset

10. The following are some of the efforts that PCP can do in acute stroke setting, except:
a. Maintaining the patient's vital signs stable
b. Providing thrombolytic therapy as soon as possible
c. Informing the nearest emergency department
d. Evaluating the signs and symptoms in stroke patients 


\section{Attitude}

Please choose an answer that you think is the most correct and most suitable for you according to your current situation.

\begin{tabular}{|l|l|l|l|l|l|l|}
\hline No. & Statements & Disagree & Rather disagree & Neutral & Rather agree & Agree \\
\hline 1. & $\begin{array}{l}\text { Stroke is one of the leading causes of death in } \\
\text { the world }\end{array}$ & & & & & \\
\hline 2. & All types of strokes are a medical emergency & & & & & \\
\hline 3. & $\begin{array}{l}\text { Stroke patients should be given treatment as } \\
\text { soon as possible }\end{array}$ & & & & & \\
\hline 4. & $\begin{array}{l}\text { Speed in providing initial treatment greatly } \\
\text { affects the prognosis of stroke patients }\end{array}$ & & & & & \\
\hline 5. & $\begin{array}{l}\text { The increased prevalence and mortality of strokes } \\
\text { need to be taken seriously }\end{array}$ & & & & & \\
\hline 6. & Stroke can cause disability for a lifetime & & & & & \\
\hline 7. & Stroke can be cured & & & & & \\
\hline 8. & Stroke can be prevented & & & & \\
\hline 9. & $\begin{array}{l}\text { All stroke suspected patients should be } \\
\text { immediately taken to the nearest hospital }\end{array}$ & & & & & \\
\hline 10. & $\begin{array}{l}\text { Initial management of a stroke patients must be } \\
\text { carried out by PCPs }\end{array}$ & & & & & \\
\hline
\end{tabular}

\section{Practice}

Please choose an answer that you think is the most correct and most suitable for you according to your current situation.

1. A 50 years old man comes to your clinic with a relative because he suddenly fell while cycling. As you check, you find that the patient has a decreased consciousness with a facial asymmetry and difficulty speaking. As a PCP, which of the following actions would you take first?
a. Evaluating the patient's sign and symptoms of stroke
b. Evaluating the patient's vital signs including breathing and circulation
c. Giving the patient Adrenaline or Noradrenaline intravenously
d. Giving the patient Aspirin orally because a stroke is suspected

2. A 60 years old woman comes to your clinic with a relative and complains of sudden difficulty speaking and partial body weakness. As you examine, you find that the patient is hypoventilating with a slight loss of consciousness. As a PCP, which of the following actions would you take first?
a. Giving oxygen to the patient to stabilize her condition
b. Evaluating the patient's sign and symptoms of stroke
c. Telling the patient's to lay down and rest so she can breath better
d. Giving the patient Adrenaline intravenously untill her condition is stable 
3. After measuring the blood sugar level of a patient with suspected stroke, you find that the patient is hyperglycemia with a blood sugar level of $230 \mathrm{mg} / \mathrm{dL}$. If a thrombolytic therapy plan will be given, what do you think is the most appropriate action to take as a PCP?

a. Giving the patient insulin until the blood sugar levels $<180 \mathrm{mg} / \mathrm{dL}$

b. Giving the patient insulin until the blood sugar levels $<80 \mathrm{mg} / \mathrm{dL}$

c. Telling the patient not to eat anything for 24 hours to lower their blood sugar level

d. Giving the patient Adrenaline or Noradrenaline intravenously every 15 minutes until the patient's blood sugar level is normal.

4. After measuring the blood sugar level of a patient with suspected stroke, you find that the patient is also experiencing severe hypoglycemia. As a PCP, what do you think is the most appropriate action to take?

a. Giving the patient Adrenaline or Noradrenaline intravenously every 15 minutes until the patient's blood sugar level is normal

b. Telling the patient to have a quick snack to increase their blood sugar level

c. Giving the patient Dextrose intravenously until the patient's blood sugar level is normal

d. Giving the patient Mannitol and keeping their blood sugar level $<80 \mathrm{mg} / \mathrm{dL}$

5. After measuring the blood pressure level of a patient with suspected stroke, you find that the patient's blood pressure level is up to $220 / 110 \mathrm{mmHg}$. If a thrombolytic therapy plan will be given, what do you think is the most appropriate action to take as a PCP?

a. Giving the patient thrombolytic therapy without lowering the blood pressure level

b. Lowering the blood pressure level to $<180 / 110 \mathrm{mmHg}$ and monitor patient's condition for 24 hours after being given thrombolytic therapy

c. Lowering the blood pressure level to $<140 / 90 \mathrm{mmHg}$ and monitor patient's condition for 24 hours after being given thrombolytic therapy

d. Lowering the blood pressure level to $<100 / 70 \mathrm{mmHg}$ and monitor patient's condition for 24 hours after being given thrombolytic therapy 